\title{
THE ACTIVITY COEFFICIENTS OF HYDROXYL ION IN SOLUTIONS OF CALCIUM HYDROXIDE AT $30^{\circ} \mathrm{C}$.
}

\author{
By E. P. Flint and Lansing S. Wells
}

\section{ABSTRACT}

Measurements of the electromotive force of the cell, $\mathrm{H}_{2} / \mathrm{Ca}(\mathrm{OH})_{2}$ (c) $\mid \mathrm{KC}$ (saturated) $\mid \mathrm{HgCl}+\mathrm{Hg}$, at $30^{\circ}$, when potentials due to the liquid junction and saturated calomel half cell were eliminated, yielded values of the electromotive force of the half cell, $\mathrm{H}_{2} \mid \mathrm{Ca}(\mathrm{OH})_{2}$ (c). From these values the $\mathrm{pH}$ and activity coefficients of hydroxyl ion in solutions of calcium hydroxide as a function of concentration have been obtained for solutions containing between 0.050 and $1.199 \mathrm{~g} \mathrm{CaO}$ per liter. A value of $K_{w}$, the dissociation constant of water, at $30^{\circ}$ was derived from the data.

\section{CONTENTS}

I. Introduction

II. Determination of the electromotive force of the cell

III. Calculation of the liquid junction potentials and the potential of the saturated calomel half cell at $30^{\circ}$

1. Potentials of the liquid junction $\overline{\mathrm{Ca}}(\mathrm{OH})_{2}(\mathrm{c}) \mid \mathrm{K} \mathrm{Cl}$ (saturated) -

2. Liquid junction potential of $\mathrm{KCl}(0.1 \mathrm{~N}) \mid \mathrm{KCl}$ (saturated) and the potential of the saturated calomel electrode at $30^{\circ}$

IV. Determination of $\mathrm{pH}, K_{w}$ and $\gamma_{O H}$

1. Calculation of $\mathrm{pH}$

2. Determination of $K_{w}$

V. Summary

3. Determination and calculation of $\mathrm{\gamma OH}^{-}$

VI. Acknowledgments.

\section{INTRODUCTION}

Calcium hydroxide in solution is one of the products of hydrolysis from the reaction of water on hydraulic cements and their constituents which are principally calcium aluminates and silicates. In a previous study ${ }^{1}$ of calcium aluminates as well as in a current investigation of the reaction of water upon calcium silicates, the $\mathrm{pH}$ of calcium hydroxide solutions has been found useful in ascertaining the constitution of calcium aluminate and silicate solutions when considered in relation to their $\mathrm{pH}$ and composition.

Since the measurements of the $\mathrm{pH}$ of the calcium hydroxide solutions afforded also a means of determining the strength of calcium hydroxide as a base, it was decided to present this phase of the investigations as a separate paper. The use in chemical industries of about half of this country's production of lime in processes involving such reactions as saponification, hydrolysis, causticization, coagulation, and neutralization emphasizes the need for such fundamental data.

${ }^{1}$ L. S. Wells, Reaction of Water on Calcium Aluminates, B.S. Jour. Research, vol. 1 (RP34), p. 951, 1928. 
J. A. Wilson ${ }^{2}$ has called attention to the lack of information upon lime solutions and recommends that the data upon barium hydroxide be used where none for calcium hydroxide is available.

The procedure followed in this investigation involved: (1) the measurement of the emf of the cell-

$$
\mathrm{H}_{2} \mid \mathrm{Ca}(\mathrm{OH})_{2} \text { (c) } \mid \mathrm{KCl} \text { (saturated) } \mid \mathrm{HgCl}+\mathrm{Hg} \text { at } 30^{\circ},{ }^{3}
$$

(2) the calculation of the liquid junction potentials, and (3) the use of a suitable value for the potential of the saturated calomel half cell. These quantities determine the potential of the half cell $\mathrm{H}_{2} \mathrm{Ca}(\mathrm{OH})_{2}$ (c) from which the $\mathrm{pH}$ and activity coefficients, $\gamma_{\mathrm{OH}^{-}}$, of calcium hydroxide solutions at concentrations varying between 0.050 and $1.199 \mathrm{~g}$. $\mathrm{CaO}$ per liter were obtained. A value for the dissociation constant of water, $K_{w}$, at $30^{\circ}$ was derived from the data.

\section{DETERMINATION OF THE ELECTROMOTIVE FORCE OF THE CELL}

A saturated calcium hydroxide solution was prepared from oxide obtained by the ignition of C.P. calcium carbonate and subsequently freed from alkalies possibly present by extraction with water. This solution was kept in a flask with an attached burette and a suitable arrangement of soda-lime tubes to exclude carbon dioxide.

Dilutions were made with $\mathrm{CO}_{2}$-free water in volumetric flasks and their concentrations checked by titration with $N / 10 \mathrm{HCl}$ standardized against a calcium hydroxide solution, the lime content of which had been determined by precipitation as the oxalate, followed by ignition to $\mathrm{CaO}$.

Incidentally, attention may be called to the convenience of saturated calcium hydroxide solution for the standardization of hydrochloric acid of $0.1 \mathrm{~N}$ concentration or less. Johnston and Grove ${ }^{4}$ have shown that the determination of lime in calcium hydroxide solutions by titration with standard hydrochloric acid, using methyl red indicator, gives results in good agreement with those obtained gravimetrically. The advantage of the use of saturated calcium hydroxide solution for standardizing hydrochloric acid lies in the fact that the original base need not be of a high degree of purity. Due to the low solubility of calcium hydroxide, alkalies may easily be extracted with water. Investigations here have shown that other impurities, such as $\mathrm{SiO}_{2}, \mathrm{Al}_{2} \mathrm{O}_{3}, \mathrm{Fe}_{2} \mathrm{O}_{3}, \mathrm{MgO}$, etc., which might be present in quicklime, are so insoluble in saturated calcium hydroxide solution that a very pure solution is easily prepared and its lime content determined as specified above.

Details of the apparatus, including the cell set-up and the air thermostat which maintained a temperature of $30^{\circ} \pm 0.05^{\circ}$, have been published previously. ${ }^{5} P t-P d$ black electrodes were used in these experiments. Twice recrystallized C.P. potassium chloride and

2 J. A. Wilson, The Chemistry of Leather Manufacture, The Chemical Catalog Co., New York, N.Y., vol. 1, 1928.

3 All temperatures in this work are expressed in the centigrade scale unless otherwise specified.

4 J. Johnston and C. Grove, Solubility of Calcium Hydroxide in Aqueous Salt Solutions, J. Am. Chem. Soc., vol. 53, p. 3976, 1931.

s See footnote 1, p. 161 . 
carefully purified mercury and calomel were used in making up the calomel half cell and bridge solution.

Measurements of emf were made immediately after preparation of the calcium hydroxide solutions. Column 1 of table 1 gives the number of the experiment; column 2, the concentration of the solutions expressed as grams $\mathrm{CaO}$ per liter; and column 3, the emf of the cell, $\mathrm{H}_{2} \mid \mathrm{Ca}(\mathrm{OH})_{2}$ (c) $\mid \mathrm{KCl}$ (saturated) $\mid \mathrm{HgCl}+\mathrm{Hg}$, at $30^{\circ}$ as read on the potentiometer. It may be noted in column 3 that the emf is recorded to 5 places for 8 of the cell measurements and to only 4 places for the remainder. The initial measurements made in the range of the more concentrated calcium hydroxide solutions were recorded to tenths of a millivolt. However, the constancy of the readings was such as to justify subsequent readings to hundredths of a millivolt.

TABLE 1.-Data obtained from measurements on the cell, $\mathrm{H}_{2}{ }^{\mathrm{E}_{1}} / \mathrm{Ca}(\mathrm{OH})_{2}(\mathrm{c})^{\mathrm{E}_{\mathrm{L}}} / \mathrm{KCl}$ (saturated) $\mathrm{E}_{2} / \mathrm{HgCl}+\mathrm{Hg}$ at $30^{\circ}$

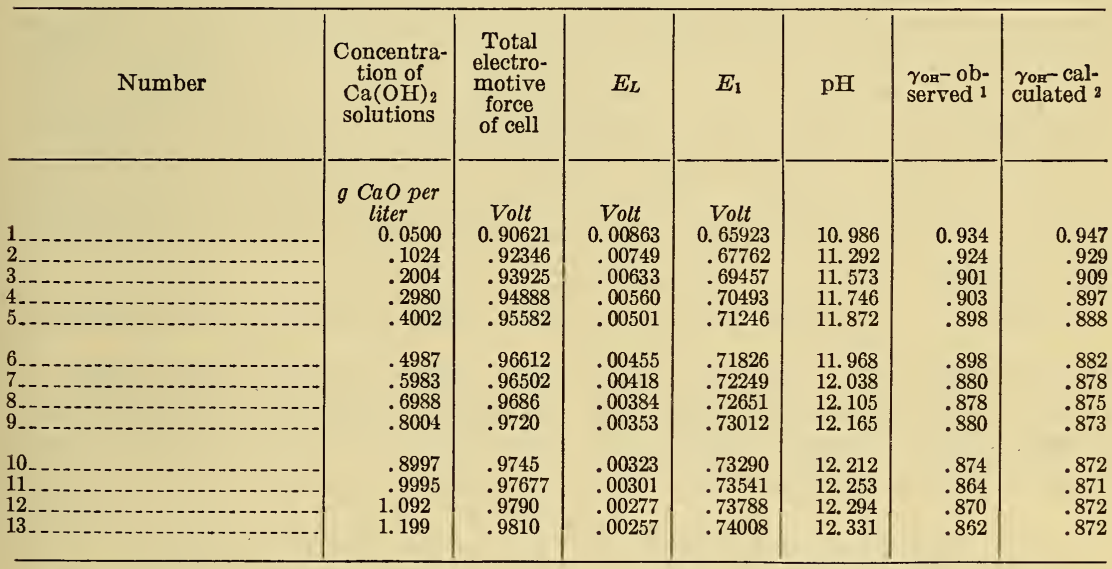

1 Observed values using the relationship $-\log _{10} \gamma_{0 \mathrm{H}^{-}}=\mathrm{p}^{\mathrm{K}} \mathrm{w}-\mathrm{pH}+\log _{10} \mathrm{C}_{\mathrm{OH}^{-}}$ 2 Calculated from the equation

$-\log _{10 \gamma O \mathrm{H}^{-}}=0.512 \sqrt{\mu}-1.096 \mu$.

\section{CALCULATION OF THE LIQUID JUNCTION POTENTIALS AND THE POTENTIAL OF THE SATURATED CALOMEL HALF CELL AT $30^{\circ}$}

\section{POTENTIALS OF THE LIQUID JUNCTION $\mathrm{Ca}(\mathrm{OH})_{2}$ (c) $\mid \mathrm{KCl}$ (saturated)}

The emf of the cell, $\mathrm{H}_{2} \mid \mathrm{Ca}(\mathrm{OH})_{2}$ (c) $\mid \mathrm{KCl}$ (saturated) $\mid \mathrm{HgCl}+\mathrm{Hg}$, is composed of potentials developed between $\mathrm{H}_{2}$ and calcium hydroxide solution; between calcium hydroxide solution and saturated potassium chloride solution; and at the mercury-calomel electrode.

Henderson ${ }^{6}$ has derived a formula for calculating liquid potentials based upon the assumption that two solutions at their junction form

\footnotetext{
${ }^{6}$ P. Henderson, Thermodnaymics of Liquids, Z. physik. Chem., vol. 59, p. 118, 1907.
} 
a continuous mixture unaffected by diffusion. Henderson's original equation is incorrect, due to an error in the derivation. The corrected formula given by Pfleiderer ${ }^{7}$ is the following:

$$
E_{L}=\frac{R T}{F} \frac{\Sigma_{1} \frac{u c}{m}-\Sigma_{1} \frac{v c^{\prime}}{m^{\prime}}-\Sigma_{2} \frac{u c}{m}+\Sigma_{2} \frac{v c^{\prime}}{m^{\prime}}}{\Sigma_{1} u c+\Sigma_{1} v c^{\prime}-\Sigma_{2} u c-\Sigma_{2} v c^{\prime}} \log _{\theta} \frac{\Sigma_{1} u c+\Sigma_{1} v c^{\prime}}{\Sigma_{2} u c+\Sigma_{2} v c^{\prime}}
$$

where $R$ is the gas constant, $T$ the absolute temperature, $F$ the Faraday and $\Sigma_{1}$ and $\Sigma_{2}$ refer to the two solutions; $u$ is the mobility of any cation at the equivalent concentration, $c$, and $m$ its valence. The terms $v, c^{\prime}$, and $m^{\prime}$ are the corresponding quantities for any anion. This equation was used in calculating the potentials of the combination $\mathrm{Ca}(\mathrm{OH})_{2}$ (c) $\mid \mathrm{KCl}$ (saturated).

This formula was derived on the assumption of complete dissociation of the electrolytes involved. In order to apply the equation to a case involving a saturated potassium chloride solution, it was modified by substitution of activity for concentration of potassium chloride. The procedure is not entirely correct, as may be discovered from the derivation of Henderson's formula, for the substitution assumes that the activity coefficient of an ion in the boundary is a function of the concentration of that ion, whereas actually the activity coefficient of an ion in the boundary is a function of the square root of the ionic strength of the mixture. This substitution of activity for concentration, however, should give a closer approximation than that furnished by equation (1).

Further, $u=\frac{\Lambda T_{C}}{F}$ and $v=\frac{\Lambda T_{A}}{F}$, where $\Lambda$ is the equivalent conductance of the electrolyte and $T_{C}$ and $T_{A}$ are the transference numbers of cation and anion, respectively, at the prevailing concentrations. Substitution of these quantities in equation (1) leads to the following expression:

$$
\begin{gathered}
E_{L}=\frac{R T}{F} \frac{(\Lambda \mathrm{c})_{\mathrm{Ca}(\mathrm{OH})_{2}}\left(1 / 2 T_{\mathrm{Ca}}-T_{\mathrm{OH}}\right)+(\Lambda \mathrm{c} \gamma)_{\mathrm{KCl}}\left(T_{\mathrm{Cl}}-T_{\mathrm{K}}\right)}{(\Lambda \mathrm{c})_{\mathrm{Ca}(\mathrm{OH})_{2}}-(\Lambda \mathrm{c} \gamma)_{\mathrm{KCl}}} \log _{\mathrm{e}} \\
\frac{(\Lambda \mathrm{c})_{\mathrm{Ca}(\mathrm{OH})_{2}}}{(\Lambda \mathrm{c} \gamma)_{\mathrm{KCl}}}
\end{gathered}
$$

where $\gamma$ is the activity coefficient of $\mathrm{KCl}$ in its saturated solution at $30^{\circ}$.

A saturated solution of potassium chloride at $30^{\circ}$ contains $272 \mathrm{~g}$ $\mathrm{KCl}$ in $1,000 \mathrm{~g}$ of solution. ${ }^{8}$ The density of such a solution ${ }^{9}$ is 1.1814 . Hence the solubility of potassium chloride at $30^{\circ}$ is $321 \mathrm{~g}$ per liter of solution and the concentration is 4.31 molar. A measurement of the specific conductance at $30^{\circ}$ gave the value 0.4271 reciprocal ohms, ${ }^{10}$ from which it follows that the equivalent conductance of a saturated potassium chloride solution at $30^{\circ}$ is 99.1 reciprocal ohms.

7 Stähler's Handbuch der Arbeitsmethoden in der anorganischen Chemie 3, p. 863, Leipzig, 1914.

8 International Critical Tables.

$\because$ Determined by Miss E. E. Hill, of this Bureau.

10 Measured with the apparatus and assistance of Dr. C. Kasper, according to the method described in B. S. Jour. Research, vol. 9 (RP476), p. 353, 1932. 
For a uniunivalent electrolyte Hückel's equation expressing activity coefficient as a function of concentration has the following form, according to Harned, ${ }^{11}$

$$
\log _{10} \gamma=\frac{-0.356 \sqrt{2 c}}{1+A \sqrt{2 c}}+B \times 2 c-\log _{10}(1+0.036 m)
$$

where $A$ and $B$ are constants characteristic of the electrolyte and $c$ and $m$ express the concentration of the electrolyte, the former in mols per liter of solution, the latter in mols per $1,000 \mathrm{~g}$ water. For $\mathrm{KCl}$ solutions at $25^{\circ}{ }^{12}$ Harned found $A=0.76, B=0.0171$. The excellent agreement which he obtained between experimentally determined values of $\gamma$ and those calculated by this formula up to $m=4$ justifies its use in calculating $\gamma$ at $m=5.01, c=4.31$. The activity coefficient of $\mathrm{KCl}$ at this concentration is thereby found to be 0.565 .

$T_{K}$, the transference number of potassium ion, in potassium chloride solution saturated at $25^{\circ}$ has the value $0.473 .{ }^{13} T_{C a}(0.012-0.020$ mols $\mathrm{Ca}(\mathrm{OH})_{2}$ per liter $)$ is 0.214 at $24.5^{\circ} .{ }^{14}$

Substituting the values of $\frac{2.303 \mathrm{RT}}{F}, T_{\mathrm{C} a}, T_{\mathrm{OH} s}(\Lambda \mathrm{c} \gamma)_{\mathrm{KCl}} T_{K}$ and $T_{\mathrm{Cl}}$ in equation (2), the following results:

$$
E_{L}=0.0601 \frac{-0.679(\Lambda \mathrm{c})_{\mathrm{Ca}(\mathrm{OH}) 2}+13.031}{(\Lambda \mathrm{c})_{\mathrm{Ca}(\mathrm{OH}) 2}-241.32}\left[\log _{10}(\Lambda \mathrm{c})_{\mathrm{Ca}(\mathrm{OH}) 2}-2.383\right]
$$

Values for $\Lambda_{\mathrm{Ca}(\mathrm{OH}) 2}$ were interpolated from measurements of equivalent conductance of calcium hydroxide solutions made at $30^{\circ}$ by Noda and Miyoshi ${ }^{15}$ and by Miller and Witt ${ }^{16}$ between 0.001 molar and saturation. The liquid potentials as calculated from equation (3) appear in column 4 of table 1.

\section{LIQUID JUNCTION POTENTIAL OF $\mathrm{KCl}(0.1 \mathrm{~N}) \mid \mathrm{KCl}$ (SATURATED) AND THE POTENTIAL OF THE SATURATED CALOMEL ELECTRODE AT $30^{\circ}$}

Riehm ${ }^{17}$ has recently determined the emf of the combination, $\mathrm{Hg}+\mathrm{HgCl}|\mathrm{KCl}(0.1 \mathrm{~N})| \mathrm{KCl}$ (saturated) $\mid \mathrm{HgCl}+\mathrm{Hg}$, over a wide range of temperature. At $30^{\circ}$ the value obtained was -0.0942 volt. ${ }^{18}$

The liquid junction potential of the cell has been calculated by Henderson's corrected formula, using the data already given for the saturated potassium chloride solution and the following values for

11 H. S. Harned, The Electromotive Force of Uniunivalent Halides in Concentrated Aqueous Solution, J.Am.Chem. Soc., vol. 51 , p. 416,1929 .

${ }_{12}$ Where data at $30^{\circ}$ are lacking in the literature, the values at $25^{\circ}$ for the activity coefficients and transference numbers neer ed for substitution in equation (2) were used. This procedure probably introduced

no error beyond the accuracy of the formula.
13 E. R. Smith, B.S.Jour. Research, vol. 6 (RP314), p. 917, 1931. D. A. MacInnes and M. Dole,

J.Am.Chem.Soc., vol. 53, p. 1357, 1931.

14 W. Bein, Z.physik. Chem., vol. 27, p. 1, 1898.

$15 \mathrm{~T}$. Noda and A. Miyoshi, Electrical Conductivity of Aqueous Solutions of Calcium Hydroxide,

J. Soc. Chem.Ind. (Japan), vol. 35, Suppl. Binding, 317-320, 1932.

${ }_{16}$ L. B. Miller and J. C. Witt, Solubility of Calcium Hydroxide, J.Phys. Chem., vol. 33, p. $285,1929$.

${ }_{17} \mathrm{H}$. Riehm, Determination of the Potential Difference between the $0.1 \mathrm{~N}$ and Saturated Calomel Electrode at $5^{\circ}$ to $50^{\circ}$, Z.physik. Chem., A160, pp. 1-7, 1932.

18 The conventions of sign of potential followed by G. N. Lewis and M. Randall, Thermodynamics, McGraw-Hill Book Co., New York, N.Y., 1923, are used throughout. 
the $0.1 N$ potassium chloride solution: $\Lambda=132,{ }^{19} T_{K}=0.497^{20}$ and $\gamma=0.764 .{ }^{21}$ Substitution of these values in equation (1) gives $E_{\mathrm{L}}=$ 0.00465 volt.

The potential of the $0.1 \mathrm{~N}$ calomel electrode at $30^{\circ}$ is -0.3372 volt. ${ }^{22}$

$E$ for the half cell $\mathrm{Hg}+\mathrm{HgCl} \mid \mathrm{KCl}$ (saturated) at $30^{\circ}$ is then $-0.3372+(0.00465+0.0942)=-0.2383_{5}$, a value approximately $5 \mathrm{mv}$ lower than that ordinarily used for the emf of the saturated calomel electrode when liquid potentials are neglected.

\section{DETERMINATION OF $\mathrm{pH}, K_{w}$, AND $\gamma_{\mathrm{OH}-}$}

\section{CALCULATION OF pH}

The emf of the cell, $\mathrm{H}_{2}\left|\mathrm{Ca}(\mathrm{OH})_{2}(c)\right| \mathrm{KCl}$ (saturated) $\mid \mathrm{HgCl}+\mathrm{Hg}$, is the algebraic sum of three quantities: $E_{1}$, the potential of the half cell $\mathrm{H}_{2} \mid \mathrm{Ca}(\mathrm{OH})_{2}(c) ; E_{\mathrm{L}}$, the potential of the junction $\mathrm{Ca}(\mathrm{OH})_{2}$ (c) $\mid \mathrm{KCl}$ (saturated); and $\mathrm{E}_{2}$, the potential of the saturated calomel half cell.

The relationship between these quantities is expressed by the equation, $E_{1}+E_{L}-E_{2}=E_{\text {total }}$, whence, on substitution of the value for $E_{2}$ derived in the preceding section,

$$
E_{1}=E_{\text {total }}-E_{L}-0.2383_{5}
$$

Column 5 of the table gives values of $E_{1}$ calculated from equation (4) using figures for $\mathrm{E}_{\text {total }}$ and $E_{L}$ given in columns 2 and 3 , respectively. Further,

$$
E_{1}=\frac{-R T}{F} \log _{\mathrm{e}} \frac{\left[H^{+}\right]}{\left(\frac{760-32}{760}\right)}
$$

where $R$ is the gas constant, $T$ the absolute temperature, $F$ the Faraday and $\left(\frac{760-32}{760}\right)$ is the partial pressure of hydrogen in atmospheres in hydrogen saturated with water vapor at $30^{\circ}$. Transforming and substituting 0.06011 , the numerical value of $2.303 \frac{R T}{F}$ at $30^{\circ}$, leads to the following expression:

$$
-\log _{10}\left[\mathrm{H}^{+}\right]=\mathrm{pH}=\frac{E_{1}}{0.06011}+0.019
$$

Column 6 of table 1 gives the $\mathrm{pH}$ of the calcium hydroxide solutions calculated from the above formula. These $\mathrm{pH}$ values are plotted in figure 1 against corresponding lime concentrations (column 2, table 1).

\section{DETERMINATION of $K W$}

By definition $\left[\mathrm{H}^{+}\right]\left[\mathrm{OH}^{-}\right]=K_{w}$ where $\left[\mathrm{H}^{+}\right]$and $\left[\mathrm{OH}^{-}\right]$are the activities of the hydrogen and the hydroxyl ion, respectively, and $K_{w}$ is the dissociation constant of water.

10 Interpolated from the data of H. C. Jones, Carnegie Inst. Wash. Pub. No. 170, 1912.

20 International critical tables.

21 See footnote 11, p. 167 .

${ }_{22}$ W. M. Clark, The Determination of Hydrogen Ions, Williams \& Wilkins Co., Baltimore, Md., 3d ed., 1928. 
Taking the logarithms of the reciprocals of the quantities in this equation and substituting for activity of the hydroxyl ion, its equivalent, the product $\mathrm{C}_{\mathrm{OH}^{-}}-\mathrm{X}_{\mathrm{OH}^{-}}$gives the following equation

$$
p K_{w}=\mathrm{pH}-\log _{10} C_{\mathrm{OH}^{-}}-\log _{10} \gamma_{\mathrm{OH}^{-}}
$$

where $p K_{w}$ represents $-\log _{10} K_{w}$ and where $C_{\mathrm{OH}^{-}}$and $\gamma_{\mathrm{OH}^{-}}$are the concentration and the activity coefficient of the hydroxyl ion, respectively.

From the Debye-Hückel theory ${ }^{23}$ the activity coefficient of a univalent ion in solution is given by the expression

$$
-\log _{10} \gamma=A \sqrt{\mu}-B_{\mu}
$$

where the constant $A=2.303 \sqrt{\frac{2 \pi \epsilon^{6} N^{4}}{1000 R^{3} D^{3} T^{3}}}$, in which $\epsilon$ is the elec-

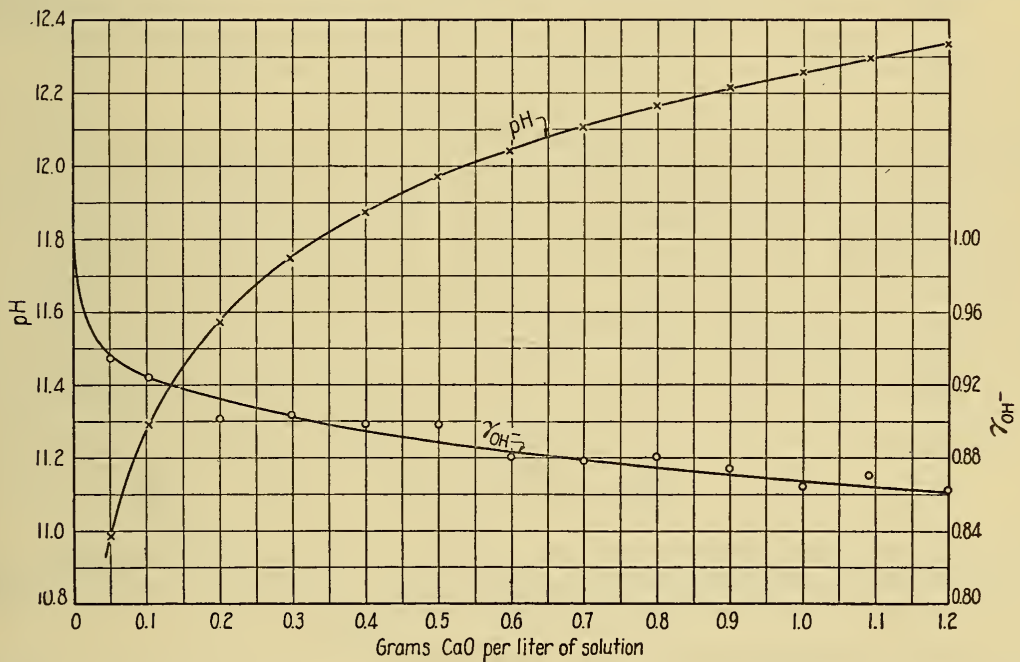

FIgURE 1.-Showing the $p H$ of solutions of calcium hydroxide and the activity coefficients of hydroxyl ion $\left(\mathrm{\gamma}_{\mathrm{OH}^{-}}\right)$as functions of the concentration of the calcium hydroxide in solution expressed as grams $\mathrm{CaO}$ per liter.

tronic charge; $N$, Avogardro's number; $R$, the gas constant; $D$, the dielectric constant of the medium; $T$, the absolute temperature. Using the value 76.75 for the dielectric constant of water at $30^{\circ}$ given by Wyman, ${ }^{24} A$ was calculated to be 0.512 at $30^{\circ} . B$ is a constant characteristic of the ion and $\mu$ the ionic strength of the electrolyte. Substituting $A \sqrt{\mu}-B \mu$ for $-\log _{10} \gamma_{\mathrm{OH}^{-}}$in equation (7), the following expression is obtained:

$$
p K_{w}=\mathrm{pH}-\log _{10} C_{\mathrm{OH}^{-}}+A \sqrt{\mu}-B_{\mu}
$$

This is the equation of a straight line.

Assuming complete dissociation, $C_{\mathrm{OH}^{-}}$in calcium hydroxide solutions is equal to the equivalent concentration of $\mathrm{Ca}(\mathrm{OH})_{2}$ and $\mu=$ $3 M$, where $M$ is the molar concentration of calcium hydroxide.

${ }^{23}$ P. Debye and E. Hückel, Physik. Z., vol. 24, p. 185, 1923.

${ }^{24} \mathrm{~J}$. Wyman, Measurement of the Dielectric Constants of Conducting Media, Phys. Rev., vol. 35 , p. $623,1923$. 
In figure $2, \mathrm{pH}-\log _{10} \mathrm{C}_{\mathrm{OH}^{-}}+A \sqrt{\mu}$ is plotted against $\mu$, using values calculated from corresponding calcium hydroxide concentrations in column 2, table 1 . The slope of the line is $B$, and the intercept is $p K_{w}$. Solution by the method of least squares showed that the probable error for a single value was 0.0031 ; the value $B=1.096 \pm$ 0.0440 , and $p K_{w}=13.765 \pm 0.008$. Hence, $K_{w}=1.72 \times 10^{-14}$.

Only two previous measurements of $K_{w}$ at $30^{\circ}$ are recorded. Lorenz and Böhi ${ }^{25}$ from measurements on the cell, $\mathrm{H}_{2}|\mathrm{HCl}(0.1 N)|$ $\mathrm{KCl}(0.1 N)|\mathrm{KOH}(0.1 N)| \mathrm{H}_{2}$, obtained $K_{w}=1.74 \times 10^{-14}$. Michaelis ${ }^{26}$ derived the value, $K_{w}=1.89 \times 10^{-14}$, from measurements on somewhat similar cells containing a hydrogen and calomel electrode.

Bjerrum and Unmack ${ }^{27}$ have measured $K_{w}$ at $0^{\circ}, 18^{\circ}, 25^{\circ}$, and $37^{\circ}$ by a method similar to that used in this investigation. The

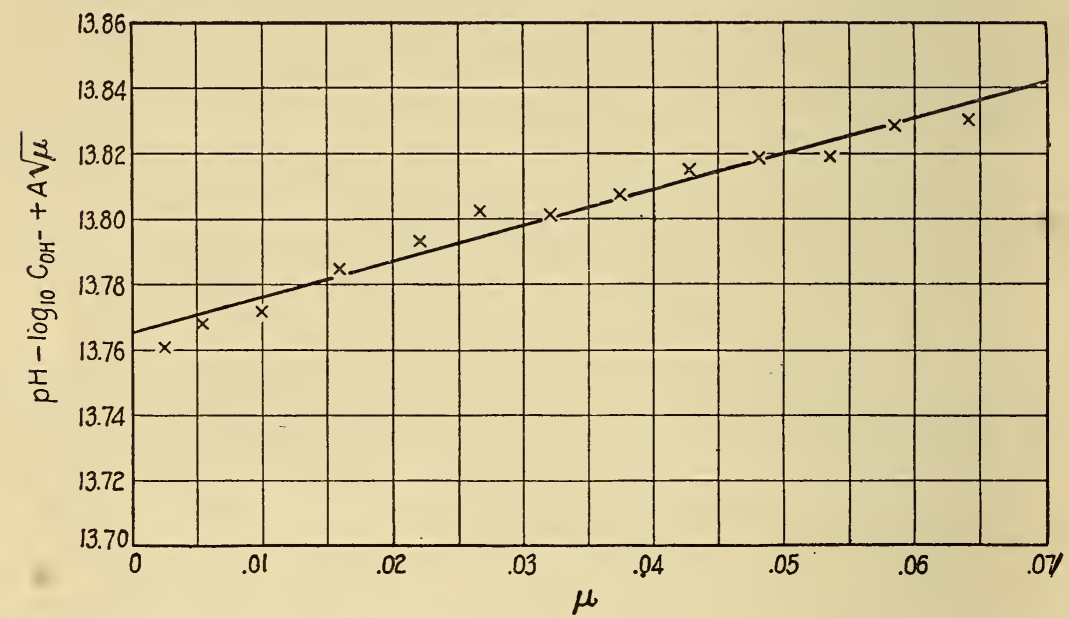

FIGURE 2.-Graphical representation of the solution or the equation $p K_{w}=p H-\log _{10}$ $C_{\mathrm{OH}^{-}}+A \sqrt{\mu}-B \mu$, wherein the quantity $p H-\log _{10} C_{\mathrm{OH}^{-}}+A \sqrt{\mu}$ is plotted as a function of the ionic strength of calcium hydroxide, $\mu$.

The intercept at the ordinate is $p K_{w}$ and the slope of the line is $B$.

equation derived from their measurements expressing variation of $K_{w}$ with temperature gives $1.55 \times 10^{-14}$ for $K_{w}$ at $30^{\circ}$.

Lewis and Randall ${ }^{28}$ have recommended that measurements of $K_{w}$ be made on cells containing no liquid junctions due to uncertainties involved in calculating liquid potentials. In this investigation choice of the method was influenced by other considerations.

\section{DETERMINATION AND CALCULATION OF $\gamma_{\mathrm{OH}^{-}}$}

Using $p K_{w}=13.765$, values of $\gamma_{\mathrm{OH}^{-}}$were calculated from equation (7) and are given in column 7 of table 1 . The variation of the activity coefficients with the concentration of $\mathrm{Ca}(\mathrm{OH})_{2}$ is shown in figure 1 .

$\gamma_{\mathrm{OH}}-$ may also be calculated from equation (8): $-\log _{10} \gamma=0.512 \sqrt{\bar{\mu}}-$ $B \mu$, where $B$ has the value 1.096 . Column 8 of table 1 contains the activity coefficients calculated from this equation. It is seen that values of $\gamma_{\mathrm{OH}^{-}}$obtained from the two independent equations are in

${ }^{25}$ R. Lorenz and A. Böhi, Contributions to the Theory of Electrolytic Ions, Z. physik. Chem., vol. 66, p. 733,1909

${ }^{26} \mathrm{~L}$. Michaelis, Die Wasserstoffionenkonzentration, Berlin, 1914.

${ }^{27} \mathrm{~N}$. Bjerrum and A. Unmack, Electrometric Measurements with the Hydrogen Electrode in Mixtures of Acids and Bases with Salts, Kl. Danske Videnskab, Math.-fys. Medd., vol. 9, pp. 83-115, 1929.

28 Thermodynamics, p. 487, MeGraw-Eill Book Co., New York, N.Y., 1923. 
agreement within the accuracy of the experiments; hence $\gamma_{\mathrm{OH}^{-}}$at $30^{\circ}$ may be calculated at any calcium hydroxide concentration by the use of equation (8).

The mean activity coefficient of calcium hydroxide is given by the expression:

$$
\gamma_{\mathrm{Ca}(\mathrm{OH})_{2}}=\sqrt[3]{\gamma_{\mathrm{Ca}}{ }^{++} \gamma_{\mathrm{OH}^{-2}}}
$$

For the concentration, $0.01976 \mathrm{~mol} \mathrm{Ca}(\mathrm{OH})_{2}$ per $1,000 \mathrm{~g}$ of water, Johnston and Grove ${ }^{29}$ obtained $\gamma_{\mathrm{Ca}(\mathrm{OH}) 2}=0.72$ at $25^{\circ}$. At this concentration $\gamma_{\mathrm{OH}^{-}}=0.872$ from equation (8). Substituting these quantities in equation (10), $\gamma_{\mathrm{Ca}}{ }^{++}=0.49$. This value of $\gamma_{\mathrm{Ca}}{ }^{++}$is in general agreement with values of the individual ion activity coefficients of divalent metallic ions given in Lewis and Randall's "Thermodynamics", table 8, p. 382. There is likewise a close correspondence between values of $\gamma_{\mathrm{OH}}{ }^{-}$given in the same table and those found in this investigation at the same ionic strengths.

\section{SUMMARY}

1. The electromotive force of the cell $\mathrm{H}_{2}\left|\mathrm{Ca}(\mathrm{OH})_{2}(c)\right| \mathrm{KCl}$ (saturated) $\mid \mathrm{HgCl}+\mathrm{Hg}$, at $30^{\circ}$ was measured for concentrations of calcium hydroxide between 0.050 and $1.199 \mathrm{~g} \mathrm{CaO}$ per liter of solution.

2. Henderson's corrected formula was applied for calculating the liquid potentials of the combination, $\mathrm{Ca}(\mathrm{OH})_{2}(c) \mid \mathrm{KCl}$ (saturated).

3 . The value -0.2384 volt for the potential of the saturated calomel half cell at $30^{\circ}$ was derived from Riehm's measurement of the electromotive force of the cell, $\mathrm{Hg}+\mathrm{HgCl}|\mathrm{KCl}(0.1 N)| \mathrm{KCl}$ (saturated) | $\mathrm{HgCl}+\mathrm{Hg}$, by correcting for the liquid potential of the combination $\mathrm{KCl}(0.1 N) \mid \mathrm{KCl}$ (saturated) and the use of W. M. Clark's value for the potential of the $0.1 \mathrm{~N}$ calomel half cell.

4. The $\mathrm{pH}$-concentration relationships of calcium hydroxide sulutions at $30^{\circ}$ are given.

5. A value for the dissociation constant of water at $30^{\circ}, K_{w}=1.72$ $\times 10^{-14}$, was determined.

6. The activity coefficients of hydroxyl ion in solutions of calcium hydroxide at $30^{\circ}$ are expressed satisfactorily by the equation, $-\log _{10} \gamma_{\mathrm{OH}^{-}}=A \sqrt{\mu}-B \mu$, where $A=0.512$ and $B=1.096$. At a calcium hydroxide concentration of 0.0198 molar, the individual ion activity coefficients are:

$$
\gamma_{\mathrm{Ca}}{ }^{++}=0.49 ; \gamma_{\mathrm{OH}^{-}}=0.87 \text {. }
$$

7. The $\mathrm{pH}$ and activity data indicate that calcium hydroxide is a strong base.

\section{ACKNOWLEDGEMENTS}

The authors wish to express their sincere thanks to J. Beek, Jr., for his suggestions, and to Dr. E. R. Smith, for his helpful advice and interest in this investigation.

Washington, May 19, 1933.

${ }^{29}$ See footnote 4, p. 164 . 